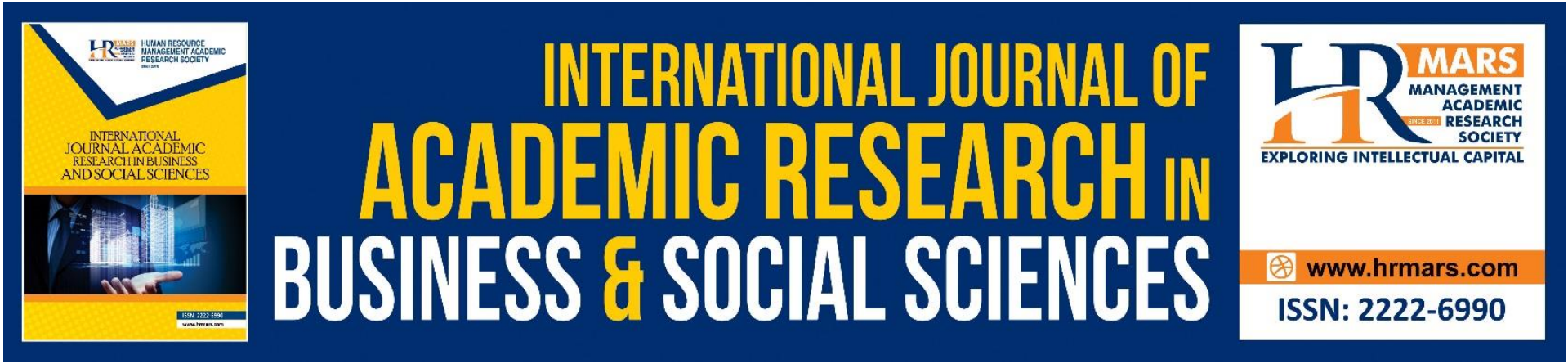

\title{
Access to Transportation: The Experiences of Women with Physical Disabilities
}

\section{Aizan Sofia Amin, Muhammad Ajib Abd Razak \& Noremy Md Akhir}

To Link this Article: http://dx.doi.org/10.6007/IJARBSS/v11-i6/10219

DOI:10.6007/IJARBSS/v11-i6/10219

Received: 01 April 2021, Revised: 04 May 2021, Accepted: 24 May 2021

Published Online: 10 June 2021

In-Text Citation: (Amin et al., 2021)

To Cite this Article: Amin, A. S., Razak, M. A. A., \& Akhir, N. M. (2021). Access to Transportation: The Experiences of Women with Physical Disabilities. International Journal of Academic Research in Business and Social Sciences, 11(6), 883-890.

Copyright: (C) 2021 The Author(s)

Published by Human Resource Management Academic Research Society (www.hrmars.com)

This article is published under the Creative Commons Attribution (CC BY 4.0) license. Anyone may reproduce, distribute, translate and create derivative works of this article (for both commercial and non-commercial purposes), subject to full attribution to the original publication and authors. The full terms of this license may be seen at: http://creativecommons.org/licences/by/4.0/legalcode

Vol. 11, No. 6, 2021, Pg. 883- 890

Full Terms \& Conditions of access and use can be found at http://hrmars.com/index.php/pages/detail/publication-ethics 


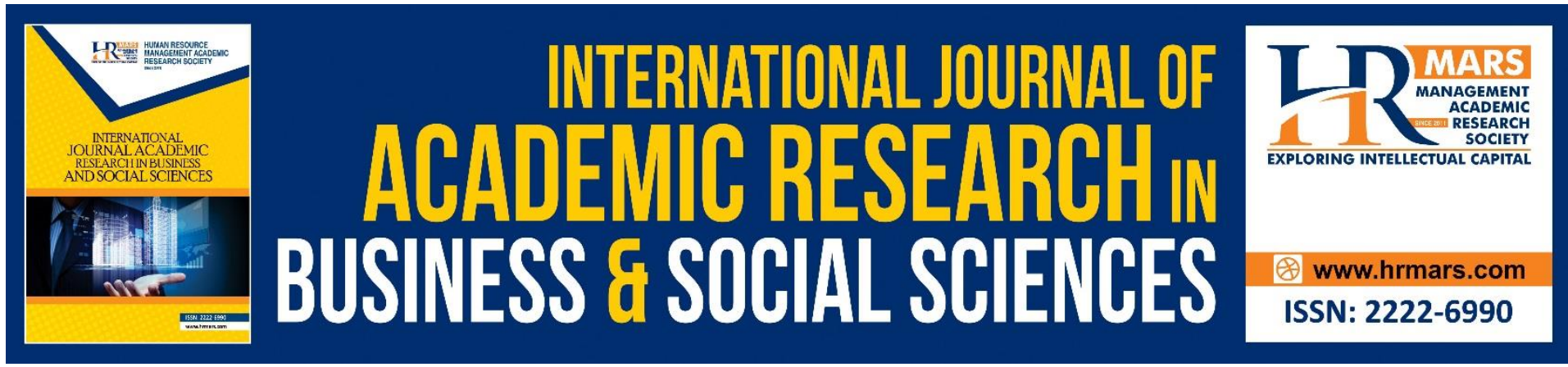

\title{
Access to Transportation: The Experiences of Women with Physical Disabilities
}

\section{Aizan Sofia Amin, Muhammad Ajib Abd Razak \& Noremy Md Akhir}

Center for Research in Psychology and Human Well-Being, Faculty of Social Science and Humanities, The National University of Malaysia, 43600 Bangi, Selangor, Malaysia

Email: muhdajib@ukm.edu.my

\begin{abstract}
Many disabled people still encounter significant barriers in getting access to transportation, especially those with physical impairments. Although the Malaysian government has developed significant disability provision, policies and legislation since the period of colonialism, disabled people still have difficulties accessing public transport. This paper, therefore, set to explore the experiences of women with physical disabilities in gaining access to public transportation. The study collected the data from in-depth interviews with 33 Malaysian women with physical impairments. The data collection took six months in interviewing twice 17 Malays, eight Chinese and eight Indian women in Malaysia. The majority of informants came from low income and rural families, and thus many of them had limited access to transportation. The findings found that many of the women interviewed revealed that they had experienced significant barriers in getting access to public transports in terms of inaccessibility of public transport and negative attitudes of the public transport providers. Therefore, this article will discuss the study's implication and how it impacts women with disabilities in Malaysia.
\end{abstract}

Keywords: Access, Public, Transport, Women, Disabilities

\section{Introduction}

This paper explores the experiences of women with physical disabilities in gaining access to public transportation. The Persons with Disabilities Act 2008 (PWDs Act, 2008) defines Persons with Disabilities (PWDs) as "those with long -term physical, mental, intellectual or sensory impairments which when interacting with various barriers, can restrict their full and effective participation in society" (PWDs Act 2008: 9 ). Therefore, this article will look at the barriers often faced by women with physical disabilities in using public transport that can restrict their full participation in economic and social aspects. Malaysia has experienced significant improvement and transformation in welfare for disabled people since the post-independence era. The Department of Social Welfare (DSW) under the Ministry of Women, Family and Community Development is the primary agency responsible for managing welfare for disabled people in Malaysia. Although the government has developed provisions, policies and laws related to PWDs, many people with disabilities still face various obstacles in their lives. Among 
the main barriers often faced by the disabled are environmental barriers and negative attitudes from the community in gaining access to public transport in Malaysia. Therefore, this article aims to explore the experiences of women with physical disabilities in Malaysia in their access to public transport.

Access to transportation and the physical environment become among the main challenges for disabled people in Malaysia. The Malaysian government has implemented the Uniform Building By-Laws (amended in 1992) and Persons with Disabilities Act 2008 to underline the right for equal access to the physical environment and public transport. However, in reality, many disabled people are still disappointed over the barriers they encountered when using public transport and getting access to public buildings. In addition, disabled people also entitle to get a 25-50 per cent discount on public transport fares. Despite these initiatives, access to public transport in many parts of the country is still inadequate for disabled people. (Kamarulzaman, 2007). Disabled persons who use mobility aids, such as wheelchairs or crutches, have to depend on taxis that are more expensive than other types of public transport. In some cases, taxi drivers have refused to accommodate wheelchair users (Kamarulzaman, 2007). As a result, many disabled people confined to their homes because of inaccessible public transport (Jayasooria, 1997). Furthermore, the government has provided incentives to the disabled who use national cars exempted from road tax and receive a 50 per cent reduction from vehicle excise duty. Even with this incentive, the disabled need to have a stable income first to buy a car when many are unemployed.

Also, included among the common problems experienced by disabled people at public places are: there are many steps and steep drops for wheelchair users, ramps are not correctly constructed, pavements with uncovered drains, control panels in elevators which are unsuitable for visually disabled or wheelchair users, narrow or too heavy doors, poorly designed guide tiles for visually disabled people, inappropriate toilet design for disabled people and improper parking space for disabled people (Kamarulzaman, 2007; Jayasooria, 1997; Tiun, 2010). Such accessibilities issues in public places faced by many disabled people in the country are complicated because many of them were unable to leave their house due to inaccessible public transports. This study, therefore, sets out to provide empirical evidence regarding barriers to transportation experience by Malaysian women with physical impairment.

\section{Methods}

This qualitative study was conducted in three different states of Peninsular Malaysia: Kuala Lumpur, Selangor and Negeri Sembilan. However, most informants formerly lived in other states in Malaysia, all over the country, including states in Borneo. The data collection of this study used in-depth interviews with 33 Malaysian women with physical (mobility) impairment. The majority of informants came from low-income and rural families. Thus many of them had limited access to basic living needs, such as healthcare, transportation, education and training, and employment. The data collection period took six months to interview 33 women with physical impairments. 17 Malays, 8 Chinese and 8 Indian women were interviewed twice between three to six months time interval between the two interviews. The informants' age ranged from 21 to 57 years old. They had a physical impairment or mobility impairment due to spinal cord injury, polio, spinal muscular atrophy, muscular dystrophy, Marfan syndrome, systemic lupus erythematosus, traumatic brain injury, 
gestational diabetes mellitus, osteosarcoma, spina bifida, teratoma, dysmelia, leg amputation and leg injury. The participants' recruitment took three different recruitment strategies via non-governmental organisations (NGOs) for disabled people (six NGOs for disabled people in Malaysia), disabled friends' networking, and snowballing. The data gathered from the indepth interviews were transcribed and then organised in computer software - QSR NVivo 9. The data were then analysed using thematic analysis (Bazeley, 2007; Creswell, 2007; Gibbs, 2011) to examine their lived experiences on their access to public transport.

\section{Results and Discussions}

Many of the women interviewed revealed that they had experienced significant barriers in getting access to public transports where they had to deal with the issues of inaccessibility and negative attitudes of the public transport providers. This section will discuss how these barriers excluded the women from broader participation in society and how this impacted their psycho-emotional wellbeing.

\section{Access to Public Transport}

Access to public transport, including buses, trains, and taxis, was for many women difficult. Most of them experienced significant mental distress when trying to overcome the structural barriers pertinent to transport. Such experience exacerbated their psycho-emotional wellbeing and amplified their disablement experiences. In Malaysia, the private vehicle (car) has become an essential and dominant mode of transport due to the inadequacies of the public transport system (Amin, 2009; Abdullah et al., 2007). There is also a well-developed 'car culture' where an increase in car ownership has been driven by rising incomes (Mohamad and Amin, 2007) and resulted in a public sector-led work project to build highways and a domestically subsidised automobile industry, especially prevalent in Peninsular Malaysia. The focus on encouraging domestic car ownership has led to a poorly integrated public transportation system, despite colonial legacies such as an extensive rail network system.

On the other hand, the cost of owning a car remains exorbitant to many. It leaves them to sign up for bank loans to buy a car which has now become a necessity, not a luxury. However, such financing options remained out of reach for those in the lower classes, the unemployed, and those on welfare. For most of the women interviewed, their low economic status prevented them from owning their vehicle, and as such, it made them dependent on public transport. The transportation scheme or assistance from the welfare state for disabled people was also inadequate. Although the government provided road tax exemption and a 50 per cent discount of excise duty for vehicles of those with a physical impairment (see Chapter 1, 1.3.2), this was only applicable to those who could afford to buy a vehicle in the first place. For those with lower income or unemployed, buying a car was not an affordable option, and thus it made them highly dependent on public transport.

Therefore, buses remained the cheapest form of public transportation and necessary for many if they wanted to remain included in mainstream life. However, for many women with mobility impairments taking the bus was not a simple matter. As Nani described:

I think my major obstacle was using buses. For example, buses on campus were not accessible for disabled people. So when they don't provide accessible transportation for disabled students, especially those who use wheelchairs, then it's very difficult. Like for me, if I wanted to go anywhere, I had to take taxis because I couldn't rely on buses [...] it's difficult for a student like me because I have little money [to hire taxi]. 
The inaccessibility issue was not only apparent for short-distance buses but also for longerdistances as Prema mentioned:

I could only go back home to my parents' house every six months. It was more difficult if I wanted to go back to my husband's hometown because we had to take a bus for like nine hours. Oh! If I took the bus, I couldn't eat, couldn't urinate, and couldn't go to the toilet. I didn't even eat for the whole day when I went back for Deepavali [a Hindu festival]. Sometimes I thought that it would be easier if we had a car so that we wouldn't have to suffer like that.

Although Malaysia has an extensive train network, the system is rather poorly maintained and integrated due to a funding deficit and a lack of supportive policies (Amin, 2009). Trains too posed obstacles for the participants - especially those in wheelchair as Yana described:

You know what, I used to take trains when I wanted to go back home during the long term holiday. I like taking the train because it is more convenient than the bus because with the bus, I can't even take the steps. But still taking trains was difficult too. It was really difficult because the train's doors that lead to the passengers seats are too small for my wheelchair. My wheelchair is big and the door is too small [...]. They asked me to walk to the seat but I couldn't. Because of that they put me at an empty space at the entrance door. But it was not safe. There was one time, the door suddenly opened when the train was moving. I was shocked! I screamed and asked them to close the door. Then they came and fixed the door. But it was traumatic, you know. It was not safe at all! I paid for my seat but I couldn't even use it and I was put just in front of the train's door. I felt upset to be treated like that as if I am not worth taking the train.

The inaccessibility of the public rail system was not only experienced in the rail compartment itself but also at the rail station as explained by Fatin, also a wheelchair user:

It depends on which rail station I take. Like for instance in X, it was fine because they had lifts. But in some other places it was not. They didn't have lifts and I needed to take a number of steps in order to go to the platform. So, it was really difficult [...]. Every time I needed to go out I had to think of all the possibilities of whether the station was accessible or not for me. It's very frustrating.

Negotiating the public transport system was not a simple issue for these women. The structural barriers significantly impacted upon them not just physically but also psychoemotionally. It affected their ability to keep in contact with family members and friends; a problem for many intensified as they often forced to live a long distance away from their family home for accessible education, training or employment. Consequently, they were marginalised and denied equal access to broader economic and social participation. As Stephanie Thomas, a disabled activist and an organiser with ADAPT $^{1}$ asserts:

It is not coincidence that transportation was such a tinderbox issue. Transportation, both symbolically and in reality, is the key to linking with others. Mobility, the ability

${ }^{1}$ ADAPT is community organisation based in Washington, DC that organises disability rights activists to engage in nonviolent direct action, including civil disobedience, to assure the civil and human rights of disabled people to live in freedom (ADAPT, 2014) 
to get out, to get around and connect with other people, is fundamental to being a part of a larger community (Thomas, 2001: viii).

\section{Disabling Attitudes and Discrimination in Accessing Public Transport}

Whilst public transport became an important option for many of the participants with low incomes, many had difficulty in accessing public buses and trains. As such they often found that using taxis was more convenient for their physical limitations especially for those in wheelchair. However in using them, they were often subjected to attitudinal barriers, including discrimination from the drivers.

Yana described her constant frustration in getting taxi services:

Many taxi drivers will not take us if we ask unless we call them first. Even at the supermarket where many taxis are there, waiting for passengers, they hardly ever want to take me with my wheelchair. They say that it's difficult to put my wheelchair in the taxi's bonnet as they use gas. Sometimes they say it will make their taxi dirty, or that my destination is too far for them, or there is a traffic jam - and many more excuses. Then on one occasion, a taxi driver refused to take me as he said now the traffic is too heavy. But two minutes later, I saw that he took a passenger although he said it was heavy traffic at the moment. I felt it was unfair to me as he could take other people but not me?

Such an incident was typical of the experiences of many of the women in wheelchairs and reflected wider attitudinal and structural discrimination. Although the DSW introduced the PWDA 2008 that included equal access to transportation, disabled people are remained discriminated against through the public transport system. Many commentators believe that this is mainly because the act does not carry any penalty, and it is reliant on the public's goodwill to conform (Jayasooria, 2000; Kuno, 2007).

Yasmin further described:

I have always had problems when getting a taxi. When I stopped them, they said that they didn't want to take me [...]. Some of them said that 'taxi drivers can't lift the wheelchair' [...] Then I told him if he wanted to charge me extra because of that, I was fine with that. This was because I had stopped many taxis but none of them wanted to take me, even though the taxis were empty [...]. Only then he was willing to take me. Then, on many occasions, they charged me extra because they had to lift my wheelchair into the car.

Prema, another wheelchair user also shared:

If you are rich, you can get all the maids and everybody to look after you. You don't feel the pain. You don't feel anything. Like people like us, we can't, you know, we, you call for a taxi, you know how much it is? Taxis don't want to take you. Sometimes you have to argue with them [...]. They don't want to have the difficulty of taking a person on a wheelchair. It's public transport. So we want, you know, taxis that are accessible to us.

This problem of gaining access to all types of public transport, including taxis, has been primarily reported by those participants who were wheelchair users. These findings were 
similar to the previous findings on access to public transport for disabled people in Malaysia, as discussed in the introduction.

\section{Conclusion}

This paper shows how socioeconomic status, infrastructure, policies, and disability directly influence the well-being of women with physical disabilities in Malaysia. Through the life experiences of women with disabilities, studies have shown that economic and geographical aspects play an essential role in how the disabilities experienced to have a significant relationship in gaining access to public transport. The physically disabled who do not have their vehicles and have low socioeconomic status have to rely entirely on public transport to move. However, inaccessibility and discrimination in obtaining public transport services is a significant obstacle for them to live their daily lives well. As a developing country and heading towards a developed country, Malaysia needs to look at how accessibility issues in urban and rural areas and poverty factors affect the physical and psycho-social well-being of the disabled so that improvement measures can be done more systematically and effectively.

Weak legal provisions such as the PWDs Act 2008, which does not have penalties for those who fail to meet the act's requirements to provide disabled-friendly public transport, are among the causes of discrimination against disabled people. In this regard, the government needs to be more severe in addressing discrimination against the disabled in gaining access to public transport. The PWDs Act 2008 needs to be reviewed and improved by placing strict penalties and law enforcement elements as a measure to eliminate discrimination against PWDs. The Disability Discrimination Act should also be introduced in Malaysia to educate the community on the rights of the disabled. For example, stern action should be taken against taxi drivers who refuse to pick up disabled passengers without reasonable excuse. Furthermore, it can ensure the well-being of the disabled to be protected from discrimination not only in the aspect of public transport but also holistically, including education, employment, housing and other social life.

Therefore, various national agencies such as the Department of Social Welfare, Ministry of Transport Malaysia, Ministry of Urban Wellbeing, Housing and Local Government and the Attorney General's Chambers need to work together in supporting the needs and abilities of the disabled to access public transport. Local authorities need to be trained and exposed to the needs of people with disabilities to provide accessible infrastructure and transportation so that facilities suitable for the disabled can be provided. Awareness of disability issues should also be introduced at all levels, such as in schools, universities and the mass media, to educate the community on the rights and needs of the disabled so that the country's accessibility can be improved better and more effectively. In conclusion, all parties, including the government and private sectors and the public, should play a significant role in supporting the right of PWDs to access public transport and full participation in society. In conclusion, this chapter has discussed how women with physical disabilities face barriers to access to public transportation that carries significant economic implications. Without good public transport, PWDs who do not have their vehicles cannot live productively because their employment and business activities often located outside the home. Therefore, all parties need to play a more proactive and progressive role in improving access to public transport so that disabled people can be independent in generating their economy. 


\section{References}

ADAPT. (2014). Welcome to ADAPT! http://www.adapt.org/main

Abdullah, N., Atiq, R. O. K. R., \& Amiruddin, I. (2007). Effect of transportation policies on modal shift from private car to public transport in Malaysia. Journal of Applied Sciences, 7(7): 1014-1018.

Amin, T. K. (2009). Financing public transport systems in Kuala Lumpur, Malaysia: challenges and prospects. Transportation, 36(3): 275-294.

Department of Social Welfare. (2009). Social Welfare Department. [Online]. [Accessed 23 January 2017]. Available from: http://www.jkm.gov.my

Jayasooria, D. (2000). Disabled People. Citizenship \& Social Work - The Malaysian Experience. London: Asean Academic Press.

Jayasooria, D., Krishnan, B., \& Ooi, G. (1997). Disabled People in a Newly Industrialising Economy: Opportunities and challenges in Malaysia. Disability \& Society, 12(3): 455-463.

Kamarulzaman, K. (2007). Adult learning for people with disabilities in Malaysia: Provisions and services. The Journal of Human Resource and Adult Learning. 3(2), pp.50-64.

Kuno, K. (2007). Does Community Based Rehabilitation Really Work? Community Based Rehabilitation (CBR) and Participation of Disabled People. ISM Research Monograph Series No. 5. Kuala Lumpur: Social Institute Malaysia.

Mohamad, J., \& Amin, T. K. (2007). The rise of the private car in Kuala Lumpur, Malaysia: assessing the policy options. International Association of Traffic and Safety Sciences, 30(1): 69-77.

Persons with Disabilities Act 2008. (2008). Persons with Disabilities Act 2008 (Act 685). Law of Malaysia.

Tiun, L. T. (2010). From Barrier-free to Universal Design: The Penang experience. International Conference on Embracing Diversity \& Creating Disability-Sensitive Communities, 28-29 July, Kuching Sarawak.

Thomas, C. (1997). The baby and the bath water: disabled women and motherhood in social context. Sociology of Health \& IIIness, 19(5): 622-643. 